\title{
Comunicación de crisis y Ayuntamientos: el papel de Telegram durante la crisis sanitaria de la COVID-19
}

Crisis communication and local governments: the role of Telegram during the crisis of COVID-19

\author{
López Tárraga, Ana Belén
} Universidad de Salamanca (USAL) ablopez@usal.es

Forma de citar este artículo:

López-Tárraga, A. B. (2020). “Comunicación de crisis y Ayuntamientos: el papel de Telegram durante la crisis sanitaria de la COVID-19", RAEIC, Revista de la Asociación Española de Investigación de la Comunicación, vol. 7, núm. 14, 104-126.

https://doi.org/10.24137/raeic.7.14.5

\section{Resumen:}

La llegada de la COVID-19 a España marcó un antes y un después en la sociedad globalizada. La comunicación de información de servicio desde las administraciones locales en situaciones de crisis ha jugado un papel esencial para mantener a la ciudadanía informada en todo momento. Telegram y sus canales de difusión han sido la herramienta elegida por muchos ayuntamientos para difundir su información. El objeto de la presente investigación es estudiar como las instituciones locales han introducido Telegram entre sus herramientas de comunicación y el uso que se le ha dado durante la 
crisis sanitaria. Los resultados muestran como el hecho de ser un medio de contacto directo con la ciudadanía y la facilidad que existe para suscribirse a los canales han llevado a los ayuntamientos a hacer un gran uso de esta aplicación de mensajería instantánea dentro de situaciones de comunicación de crisis como la vivida en la primavera de 2020 .

Palabras clave: Ayuntamientos, comunicación de crisis, mensajería instantánea, Telegram, COVID-19.

\section{Abstract:}

The arrival of COVID-19 to Spain marked a significant change in our globalized society. Communication of service information from local administrations in crisis situations has played an essential role in keeping citizens informed at all times. Telegram and its broadcasting channels have been the tool chosen by many municipalities to disseminate their information. The purpose of this research is to study the way in which local institutions have introduced Telegram among their communication tools and the use it has been given during the health crisis. The results show how the fact of being a means of direct contact with the citizenry and the ease that exists to subscribe to their channels have led the town councils to make great use of this instant messaging application within crisis communication situations such as that experienced in Spring 2020.

Palabras clave: Town hall, crisis communication, instant messaging, Telegram, COVID19.

\section{INTRODUCCIÓN}

La llegada de la crisis sanitaria a España provocada por el SARS-CoV-2, conocido coloquialmente como COVID-19 ha puesto de manifiesto el poder real que tiene el mundo globalizado e interconectado en el que vivimos. El virus, que apareció a finales de diciembre de 2019 en la provincia de Hubei en Wuhan, China (Koury y Hirschhaut, 2020), se ha extendido a lo largo del planeta en cuestión de meses provocando 
centenares de víctimas. Un problema global sin precedentes donde la comunicación directa ha jugado un papel esencial en la concienciación ciudadana sobre el virus, su propagación y cómo frenarlo. Al mismo tiempo que la comunicación ha actuado como medio educador de la sociedad global ante una situación nunca antes vivida en el siglo XXI.

La crisis sanitaria generada por la COVID-19 ha frenado el trascurso de la llamada 'sociedad moderna líquida' de Bauman: esa sociedad del cambio constante, donde las formas de actuar de sus individuos cambian antes de consolidarse, pero dentro de un orden, como si de un bucle se tratara (Bauman, 2005, p. 9). La pandemia ha roto con el desarrollo de las formas de vida actual, generando inestabilidad y temor entre la ciudadanía. Ni la sociedad, ni las formas de Gobierno actuales han vivido una situación así a nivel global más allá de la 'gripe española' que tuvo lugar de 1918 a 1920. Ejemplos de alertas sanitarias como las vacas locas o la gripe aviar, no alcanzaron en su momento los índices de mortalidad generados por la COVID-19 en los países considerados como desarrollados (Fernández, 2020, p. 13).

La gestión de la comunicación de crisis ha jugado un papel fundamental en este contexto para transmitir a la ciudadanía calma, pero sobre todo fuerza para superar esta situación para la que no había precedentes. De hecho, esta ha sido una de las situaciones donde el concepto de crisis como "fenómeno grave, delicado y peligroso" ha sido utilizado correctamente (Losada, 2010, p. 23). La credibilidad de las fuentes institucionales ha cobrado especial relevancia, y ante este contexto coyuntural, las redes sociales de las instituciones se han alzado como uno de los principales medios de difusión de información oficial como fórmula de combate ante bulos y fake news.

Dentro del gran abanico que componen las administraciones públicas, los ayuntamientos, la administración más cercana a nivel local a la ciudadanía han sido fundamentales en la información directa con los vecinos y vecinas de un municipio. Informar, informar e informar, a través de todos los canales posibles ha sido la clave para combatir los bulos (López, 2020b). En este contexto, el uso de mensajería instantánea se ha convertido en el canal de transmisión informativa directa con la 
ciudadanía. De todas las redes sociales, los ayuntamientos se han decantado por ofrecer toda la información de servicio ciudadana a través de sus propios canales de Telegram, ejerciendo las funciones del bando tradicional (Moltó, 2020). Pero, ¿por qué Telegram?

El presente artículo trata de analizar por qué los ayuntamientos han apostado por la red social Telegram como eje conductor de la información de servicio durante la pandemia. Como casos de referencia donde esta red social se ha utilizado en momentos de crisis, se ha tomado el caso de las revueltas de Irán de diciembre 2017 (Fernández, 2018, p. 123); y el caso de 'Tsunami Democràtic' (Méndez, 2019). Respecto a los ayuntamientos, el estudio tomado como punto de partida ha sido el realizado por la periodista y funcionaria experta en Redes Sociales y Marca Personal en las Administraciones Públicas, Amalia López Acera en enero de 2020. Si bien, los datos del citado estudio han evolucionado dado que muchos ayuntamientos han creado su canal de Telegram durante la crisis sanitaria y otros han visto aumentar el número de seguidores exponencialmente.

\section{REVISIÓN DE LITERATURA}

La comunicación de crisis se hace necesaria en el momento en que una situación donde se producen unos hechos que rompen la estabilidad y cambia el desarrollo habitual de los acontecimientos, los cuáles el público demandará una explicación (Enrique, 2013, p. 117). Ante esta situación, la respuesta informativa por parte de la organización/institución ha de ser anticipada, "no hay que perder la oportunidad de ser los primeros"; ágil, "hay que reaccionar en todo momento con celeridad, sin perder el tiempo"; tiene que haber calidad informativa "aportar la mejor información"; veraz "hay que decir la verdad por dolorosa o perjudicial que pueda llegar a ser" (Westphalen y Piñuel, 1993). Los perfiles de redes sociales y los canales de mensajería instantánea son herramientas que cumplen estas características y por ello, desde las que las organizaciones/instituciones pueden hacer llegar la información al público de manera eficaz (Guzmán, 2018, p. 197).

Hay que matizar en este punto la diferencia existente entre el concepto de red social y mensajería instantánea. En el ámbito de la sociología encontramos la definición de este 
concepto del antropólogo Barnes donde afirma que "cada persona está, por así decirlo, en contacto con cierto número de otras personas, algunas de las cuales están en contacto entre sí y otras no. Creo conveniente denominar red a un campo social de este tipo" (Barnes, 1954). Esta definición es aplicable a lo que en la actualidad conocemos como redes sociales y que el diccionario panhispánico de español jurídico define como "Servicio de la sociedad de la información que ofrece a los usuarios una plataforma de comunicación a través de internet para que estos generen un perfil con sus datos personales, facilitando la creación de comunidades con base en criterios comunes y permitiendo la comunicación de sus usuarios, de modo que pueden interactuar mediante mensajes, compartir información, imágenes o vídeos, permitiendo que estas publicaciones sean accesibles de forma inmediata por todos los usuarios de su grupo" (Diccionario panhispánico del español jurídico, 2020).

Finalmente, se ha de distinguir entre redes sociales y mensajería instantánea de difusión. Mientras que las redes sociales como Facebook, Twitter o Instagram son canales multidireccionales, es decir, permiten al receptor interactuar como el emisor a través de mensajes, las aplicaciones de grupos de difusión de la aplicación de mensajería instantánea WhatsApp o los canales de difusión en Telegram no pueden ser considerados como redes sociales como tales, ya que son vías unidireccionales que no permiten al receptor intercambiar impresiones sobre la información con el emisor (Villar, 2016, pp. 18-23).

Telegram es una aplicación de mensajería instantánea desarrollada por los hermanos rusos Nikolái y Pável Dúrov en 2013. De un modo similar a WhatsApp permite a los usuarios enviar y recibir mensajes directos de texto y multimedia sin ser necesario disponer de una conexión a Internet de gran velocidad (Fernández, 2018, p. 133). WhatsApp continúa siendo la aplicación más utilizada de mensajería instantánea por la población mundial. Según anunció Facebook, la empresa subsidiaria de WhatsApp en febrero de 2020, la aplicación es usada en el mundo por 2.000 millones de personas (Ramírez, 2020). La seguridad, la privacidad y la posibilidad de crear canales de difusión directos y unidireccionales (López, 2020 A) son algunas de las características que han 
llevado a Telegram a ser la aplicación de mensajería alternativa utilizada por movimientos sociales como las protestas de Irán de 2017 o de Cataluña en 2019.

A nivel internacional, como ejemplo podemos citar el papel que jugó Telegram en las revueltas de Irán de diciembre de 2017. Centenares de iraníes de clases populares se manifestaron contra el presidente Hassan Rouhaní y el Líder Supremo en la segunda ciudad del país, Mashad. Fueron protestas de origen confuso, porque no solo iban contra la política económica del Gobierno, sino que también estaban el régimen islámico y su máximo representante, Alí Jamenene; y que se extendieron rápidamente a otras ciudades de Irán como Hamadán, Qom o la capital Teherán. El origen y la rapidez de la difusión fue lo que más sorprendió a los observadores (Fernández, 2018, p. 126).

La clave, aparentemente, fue Telegram. A mediados de 2014 la población iraní comenzó a utilizar esta aplicación de mensajería en su día a día para comunicarse. Con la introducción de los canales de comunicación en septiembre de 2015, los usuarios comenzaron a suscribirse a ellos para estar al día de la información de interés (Fernández, 2018, p. 135). En el momento de las protestas, 40 de los 46 millones de usuarios de telefonía móvil, usaban Telegram. Según las autoridades del país los diferentes grupos contrarrevolucionarios y establecidos fuera de Irán escogieron Telegram (García, 2018). Actualmente, la aplicación se encuentra prohibida en el país y el Gobierno la ha bloqueado por completo (Espinosa, 2018).

A nivel nacional, puede citarse el caso de 'Tsunami Democràtic' donde Telegram fue la herramienta de difusión instantánea de la información. Esta plataforma fue creada en agosto de 2019 en Cataluña como respuesta contraria a la sentencia del juicio del 'Procès'. En este caso, la plataforma se valió del gran número de seguidores de su cuenta de Twitter, para hacer un llamamiento a los usuarios con el fin de seguir su canal de Telegram. En cuestión de semanas, el canal superó los 380.000 suscriptores llegando a ocupar el puesto número 85 del ranking según la web especializada Telegram Analytics (Lavanguardia.com, 2019). Este canal sirvió al movimiento para difundir sus objetivos, así como los lugares y horas de las protestas. 


\subsection{TELEGRAM Y AYUNTAMIENTOS: EL VALOR DE COMUNICAR EN LA ADMINISTRACIÓN PÚBLICA EN UNA SITUACIÓN DE CRISIS}

El valor de comunicar desde lo público es fundamental para generar confianza en la Administración Pública entre los diferentes ámbitos que componen la sociedad. Según explica doctora en Comunicación, María José Canel (Canel, 2018, pp. 93-94), la comunicación tiene un papel central en lo público porque:

- Genera beneficio mutuo entre la institución y la sociedad porque activa una interacción continuada.

- Es multifacética, es decir, incluye medidas para los diferentes ámbitos (económico, social...).

- Es multidimensional ya que tiene en cuenta la relación de la administración con los diferentes públicos.

- Es cross-temporal porque no solo tiene vigencia en el corto plazo, sino que perdura en el medio y largo plazo.

- Es cross-nivel porque se construye con relaciones que superan a la propia organización.

- Es cross-sectorial porque para crearlo es necesario ir más allá del propio ámbito de la Administración Pública creando alianzas con el sector privado.

- Es multi-stakeholder porque establece los canales necesarios para generar feedback para evaluar los distintos criterios de valor público.

- Comparte autoridad porque para la creación se ha de escuchar y contar con el saber de actores externos a la organización.

Todos estos criterios se vuelven esenciales, aún más si cabe, durante una situación de crisis, ya que la ciudadanía ante lo desconocido necesita depositar su confianza en las instituciones. Una confianza que se logra si la comunicación es capaz de poner en valor la buena gestión pública (Canel, 2018, p. 114). En esta situación los perfiles oficiales de las redes sociales de las entidades locales se tornan un medio directo y eficaz de contacto con la sociedad durante una crisis. Una herramienta cercana donde no se precisa de los medios de comunicación tradicionales para hacer llegar a los habitantes 
de un determinado municipio la información de servicio. Además, las redes sociales son generadoras de comunidad, ya que las siguen o se suscriben todas aquellas personas que desean mantenerse informadas sobre un aspecto determinado (Losada, 2010, p. 110).

Desde el ámbito de la comunicación institucional, si existe algo que la crisis sanitaria ha puesto de manifiesto es el hecho que la comunicación de las instituciones está al servicio de la ciudadanía, sobre todo en periodos de crisis. Según explica el asesor y consultor de comunicación, Antoni Gutiérrez-Rubí (Gutiérrez-Rubí, 2020), la comunicación institucional debe:

1. Primar la información sobre la publicidad.

2. Mostrar claridad y no ser compleja o difícil de entender para la ciudadanía.

3. Ser directa, pues las ruedas de prensa ya no sirven. Ahora lo que el público pide son intervenciones en directo como las que permiten las distintas plataformas de redes sociales.

4. Mostrar a las personas los comportamientos y no las normas, es decir, que lo que se aprecie en las imágenes o vídeos sean ejemplos de esos comportamientos que regulan las normas.

5. Ser una conversación. Las instituciones han de ser capaces de saber cuál es la información que les demanda la ciudadanía.

6. Ser empática e ir al compás de la situación coyuntural del momento.

7. Defender lo público para construir paso a paso el sentimiento de pertenencia a una comunidad.

8. Construir esa comunidad a partir de las herramientas de difusión de la información como son las aplicaciones de mensajería y las redes sociales.

9. Apostar por datos locales. Tomar consciencia de la importancia que tienen los datos locales para saber qué es lo que quieren las personas de ese lugar concreto.

10. Ser una comunicación que se encuentre adaptada al espacio. 
Del mismo modo que los movimientos sociales de Irán y Cataluña, citados anteriormente, eligieron Telegram para comunicarse directamente con la ciudadanía, los Ayuntamientos han optado progresivamente por introducir esta herramienta de mensajería instantánea como medio de difusión de la información local.

\section{METODOLOGÍA}

El presente artículo de investigación tiene como objetivo responder a las dos cuestiones siguientes:

- ¿Cuáles han sido las causas que han llevado a los ayuntamientos a optar por la creación de un canal de Telegram municipal para la difusión de la información municipal?

- ¿Qué papel ha jugado esta herramienta de mensajería instantánea durante la crisis sanitaria generada por la COVID-19?

En un primer momento, para seleccionar la muestra de estudio se tomó como referencia la entrada del blog personal de la periodista funcionaria, Amalia López Acera, que publicó el 28 de enero de 2020. En este artículo elaboró un listado de los 71 Ayuntamientos que en aquel momento tenían activo su canal Telegram (López, 2020 C).

Como bien argumenta López Acera, los datos sobre el número de suscriptores pertenecen a ese día concreto de la publicación, ya que son datos vivos que están en constante cambio. También explica que para la creación del listado tuvo en cuenta los canales en activo, ya que las redes sociales son una herramienta de uso constante y la no publicación en un periodo de tiempo se considera inactivo. Siguiendo estos parámetros para determinar la muestra objeto de estudio para la elaboración de este artículo se ha realizado un seguimiento de la evolución del número de suscriptores de los 50 primeros canales tomada del listado citado anteriormente desde que comenzó el estado de alarma el 14 de marzo hasta el 20 de mayo de 2020.

Además del seguimiento, y dado que diariamente existía la posibilidad que algunos de los Ayuntamientos de los más de 8.000 que componen el país abriera su canal, a diario se ha dedicado tiempo a realizar una búsqueda sobre nuevos canales. En ella, se han 
tenido en cuenta las lenguas cooficiales que poseen diversas comunidades autónomas como son el gallego en Galicia; el euskera en el País Vasco; y el catalán en Cataluña, Comunidad Valenciana e Islas Baleares. Para la búsqueda se introdujo la palabra 'Ayuntamiento' seguida del nombre de los municipios, así como sus correspondientes traducciones en las diferentes lenguas y abreviaturas más comunes como se muestra en la Tabla 1.

Tabla 1. Criterios utilizados para la búsqueda de nuevos canales de Telegram de ayuntamientos

\begin{tabular}{|c|c|}
\hline \multicolumn{2}{|c|}{ Búsqueda en castellano } \\
\hline Ayuntamiento + Nombre del municipio & Nombre del municipio + Ayuntamiento \\
\hline $\begin{array}{c}\text { Abreviado: } \\
\text { Ayto. + Nombre del municipio }\end{array}$ & $\begin{array}{c}\text { Abreviado: } \\
\text { Nombre del municipio + Ayto. }\end{array}$ \\
\hline \multicolumn{2}{|c|}{ Búsqueda en galego } \\
\hline Concello + Nombre del municipio & Nombre del municipio + Concello \\
\hline Abreviado: & Abreviado: \\
\hline Conc. + Nombre del municipio & Nombre del municipio + Conc. \\
\hline Udala + Nombre del municipio & Nombre del municipio + Udala \\
\hline Abreviado: & Abreviado: \\
\hline Udtx. + Nombre del municipio & Nombre del municipio + Udtx. \\
\hline \multicolumn{2}{|c|}{ Búsqueda en catalán } \\
\hline Ajuntament + Nombre del municipio & Nombre del municipio + Ajuntament \\
\hline Abreviado: & Abreviado: \\
\hline Aj. + Nombre del municipio & Nombre del municipio + Aj. \\
\hline
\end{tabular}

Fuente: Elaboración propia.

Tras realizar el trabajo de seguimiento y búsqueda de aparición de nuevos canales los resultados finalmente obtenidos fueron los que se muestran en la Tabla 2. Aclarar que en la tabla se muestran 51 ayuntamientos, en lugar de 50 como se ha comentado anteriormente. Esto se debe a que los dos últimos consistorios de la tabla (Seva y Ademuz) poseían el mismo número de suscriptores al cerrar el periodo de estudio y como reconocimiento al trabajo que se realiza desde las entidades se han incluido ambos. También cabe subrayar que una vez finalizó el periodo de seguimiento, nuevas administraciones locales como León abrieron su canal de Telegram (aytoleon.es, 2020) dejando patente que los datos cambian a gran velocidad. Los presentes resultados no dejan de ser una muestra de estudio para la elaboración de la investigación.

Tabla 2. 50 primeros Ayuntamientos de España con canal de Telegram ordenados por volumen de suscriptores 


\begin{tabular}{|c|c|c|c|c|}
\hline & AYUNTAMIENTO & CANAL & SUSCRIPTORES & CREACIÓN \\
\hline 1 & San Vicente del Raspeig & @aytoraspeig & 2.838 & 2020 \\
\hline 2 & La Vall d’Uixó & @ajlavallduixo & 2.764 & 2017 \\
\hline 3 & Sabadell & @AjSabadell & 2.419 & 2020 \\
\hline 4 & Vic & @aj vic & 2.402 & 2020 \\
\hline 5 & Barcelona & @BcnAjuntament & 2.359 & 2020 \\
\hline 6 & Sueca & @AjuntamentdeSueca & 2.202 & 2019 \\
\hline 7 & Manresa & @AjuntamentdeManresa & 1.648 & 2020 \\
\hline 8 & Torelló & @ajtorello & 1.537 & 2020 \\
\hline 9 & Lleida & @lapaeriasexplica & 1.530 & 2020 \\
\hline 10 & Benicarló & @benicarlo & 1.334 & 2017 \\
\hline 11 & Castellar del Vallès & @castellarvalles & 1.290 & 2020 \\
\hline 12 & Alcantarilla & @AlcantarillaalDia & 1.240 & 2019 \\
\hline 13 & Figueres & @ajuntamentdefigueres & 1.225 & 2020 \\
\hline 14 & Calp & @AyuntamientodeCalp & 1.213 & 2019 \\
\hline 15 & Vilanova i la Geltrú & @vilanovailageltru & 1.182 & 2020 \\
\hline 16 & Los Alcázares & @ayuntamientodelosalcazares & 1.181 & 2019 \\
\hline 17 & Xàbia & @ajuntamentdexabia & 1.150 & 2020 \\
\hline 18 & Canet de Mar & @ajcanetdemar & 1.080 & 2020 \\
\hline 19 & Lorca & @AytoLorca & 1.073 & 2020 \\
\hline 20 & Vacarisses & @ajvacarisses & 1.044 & 2017 \\
\hline 21 & Alzira & @ClauAgenda & 1.032 & 2019 \\
\hline 22 & Cártama & @ayuntamientodecartama & 1.029 & 2018 \\
\hline 23 & El Prat & @ajelprat & 983 & 2017 \\
\hline 24 & Ciudad Rodrigo & @ahoraciudadrodrigo & 974 & 2019 \\
\hline 25 & Girona & @ajuntamentdegirona & 886 & 2019 \\
\hline 26 & Amposta & @ajamposta & 907 & 2020 \\
\hline 27 & Yecla & @aytoyecla & 881 & 2020 \\
\hline 28 & Cieza & @AyuntamientodeCieza & 768 & 2019 \\
\hline 29 & Alcañiz & @alcaniz ayuntamiento & 777 & 2019 \\
\hline 30 & Catarroja & @ajuntcatarroja & 763 & 2017 \\
\hline 31 & Mollerussa & @ajmollerussa & 733 & 2020 \\
\hline 32 & Sant Quirze del Vallès & @avisosSQV & 715 & 2020 \\
\hline 33 & Sarrià de Ter & @Sarriadeter & 704 & 2018 \\
\hline 34 & Salt & @ajuntamentdesalt & 645 & 2020 \\
\hline 35 & Valencia de Don Juan & @ValenciaDeDonJuan & 637 & 2019 \\
\hline 36 & Taradell & @ajtaradell & 609 & 2020 \\
\hline 37 & Palafrugell & @ajpalafrugell & 596 & 2020 \\
\hline 38 & Les Borges del Camp & @ajlesborges & 595 & 2020 \\
\hline 39 & Sant Celoni & @ajsantceloni & 575 & 2018 \\
\hline 40 & Centelles & @ajuntamentcentelles & 542 & 2020 \\
\hline 41 & Sevilla & @ayuntamientodesevilla & 542 & 2018 \\
\hline 42 & La Vall d'en Bas & @PregonerBas & 527 & 2019 \\
\hline 43 & El Vendrell & @covid19alvendrell & 513 & 2020 \\
\hline 44 & Santa Coloma de Cervera & @StaColomaC & 508 & 2020 \\
\hline 45 & La Nucía & @LaNuciaES & 507 & 2019 \\
\hline
\end{tabular}




\begin{tabular}{|l|c|c|c|c|}
\hline $\mathbf{4 6}$ & Castellbisbal & @ajcastellbisbal & 483 & 2019 \\
\hline $\mathbf{4 7}$ & Benalmádena & @ayuntamientobenalmadena & 463 & 2019 \\
\hline $\mathbf{4 8}$ & Calatayud & @aytocyud & 459 & 2020 \\
\hline $\mathbf{4 9}$ & Celrà & @ajuntamentcelra & 407 & 2020 \\
\hline $\mathbf{5 0}$ & Seva & @ajseva & 402 & 2019 \\
\hline $\mathbf{5 0}$ & Ademuz & @bandosademuz & 402 & 2018 \\
\hline
\end{tabular}

Fuente: Elaboración propia.

Obtenida la muestra, para conocer cuáles habían sido los motivos por los que estas cincuenta administraciones locales habían abierto un canal de Telegram institucional, se envió un cuestionario de respuesta abierta a través de email y mensaje privado de Facebook a los 51 Ayuntamientos de la tabla. Los contactos de correo electrónico, así como los perfiles de la red social Facebook han sido extraídos de las webs oficiales de cada uno de los consistorios. El cuestionario fue elaborado mediante la aplicación de documentos de Google que permite realizar formularios. Para que la respuesta fuera totalmente fiable, en el cuerpo del email y mensaje se especificó que iba dirigido a la/s persona/s encargadas de gestionar el canal de Telegram.

En la encuesta se realizaban las siguientes preguntas:

1. Indique el nombre de su Ayuntamiento y el cargo que desempeña dentro del mismo.

2. ¿Cuántos habitantes tiene su municipio?

3. ¿Cuáles fueron los motivos que le llevaron a abrir el canal de Telegram municipal? Explíquelos en unas breves líneas. En caso de haber creado el canal de Telegram durante la crisis sanitaria indique los motivos.

4. ¿Qué papel ha jugado Telegram en su administración durante la crisis sanitaria?

5. ¿Qué material ha sido el más utilizado en Telegram a la hora de comunicar: vídeos, infografías, imágenes...? Indique los motivos.

6. ¿Cuántos suscriptores tiene su canal? ¿Ha experimentado un aumento de suscriptores durante la crisis sanitaria?

7. Desde su punto de vista, ¿qué diferencia Telegram del resto de redes sociales?

8. La gestión del canal de Telegram ¿la realiza el propio Ayuntamiento o es una empresa externa la que lleva las redes sociales? 
9. En caso de ser el Ayuntamiento el gestor del canal ¿Cuántas personas gestionan el canal de Telegram municipal? Indique el número y el cargo de los gestores de la red social.

10. Si tiene algo que matizar o destacar puede desarrollarlo aquí.

El margen de tiempo que se dio para contestar fue de 13 días, concretamente del 21 de mayo al 2 de junio de 2020. De los 51 Ayuntamientos a los que se les envió la encuesta se obtuvo la respuesta de 29 de ellos. Por orden de recepción estas fueron las administraciones locales que contestaron: Castellbisbal, Centelles, Prat de Llobregat, Canet de Mar, Sueca, La Vall d'en Bas, Catarroja, El Vendrell, Ademuz, Sevilla, Torelló, Xàbia, Cártama, Alcantarilla, Vacarisses, Lorca, Yecla, Lleida, Palafrugell, Los Alcázares, Calatayud, La Vall d'Uixó, Ciudad Rodrigo, Castellar del Vallés, Alcañiz, Valencia de Don Juan, San Vicente del Raspeig, Benicarló y La Nucía.

Finalmente, las respuestas recibidas han sido analizadas utilizando metodología cualitativa. Para ello, se ha usado el software de análisis de datos cualitativos 'Nvivo'. Las respuestas fueron codificadas a través de ocho etiquetas: apertura durante la crisis, aumento de suscriptores, directo, infografías, todo tipo de documentos, no hay ruido, gestión profesional desde el ayuntamiento, privacidad. La elección de las etiquetas se elaboró cruzando las respuestas comunes recibidas por parte de las diferentes administraciones locales.

\section{RESULTADOS}

Una vez obtenidos los resultados observamos que la llegada de Telegram a la administración local se produjo en torno a 2017, año en el que Ayuntamientos como la Vall d'Uixò (Castellón) o Vacarisses (Barcelona), abrieron sus canales municipales de comunicación en Telegram. En los años posteriores se sumaron entidades de diferentes puntos de España como Sevilla o Cártama (Málaga) en 2018; Calp (Alicante) o Alcantarilla (Murcia) en 2019. En 2020 se abrieron la mayoría de canales de Telegram. La clasificación de aparición de canales de Telegram en los ayuntamientos por año de creación y el volumen porcentual de los mismos puede observarse en la Tabla 3. 
Tabla 3. 50 primeros Ayuntamientos que poseen canal de Telegram ordenados por fecha de creación.

\begin{tabular}{|c|c|c|}
\hline Año de creación & Canales & Porcentaje \\
\hline 2017 & $\begin{array}{c}5 \text { canales: La Vall d’Uixó, } \\
\text { Benicarló, Vacarisses, El Prat y } \\
\text { Catarroja. }\end{array}$ & $10 \%$ \\
\hline 2018 & $\begin{array}{l}5 \text { canales: Cártama, Sarriá de } \\
\text { Ter, Sant Celoni, Sevilla y } \\
\text { Ademuz. }\end{array}$ & $10 \%$ \\
\hline 2019 & $\begin{array}{l}15 \text { canales: Sueca, Manresa, } \\
\text { Torelló, Lleida, Alcantarilla, } \\
\text { Calp, Vilanova i la Geltrú, Los } \\
\text { Alcázares, Alzira, Ciudad } \\
\text { Rodrigo, Girona, Cieza, Alcañiz, } \\
\text { Valencia de Don Juan, La Vall } \\
\text { d'En Bas, La Nucía, } \\
\text { Castellbisbal, Benalmádena y } \\
\text { Seva. }\end{array}$ & $30 \%$ \\
\hline 2020 & $\begin{array}{l}26 \text { canales: San Vicente del } \\
\text { Raspeig, Sabadell, Vic, } \\
\text { Barcelona, Castellar del Vallés, } \\
\text { Figueres, Xàbia, Canet de Mar, } \\
\text { Lorca, Amposta, Yecla, } \\
\text { Mollerrusa, Sant Quirze del } \\
\text { Vallés, Salt, Taradell, } \\
\text { Palafrugell, Les Borges del } \\
\text { Camp, Centelles, El Vendrell, } \\
\text { Santa Coloma de Cervera, } \\
\text { Calatayud y Celrà. }\end{array}$ & $50 \%$ \\
\hline
\end{tabular}

Fuente: Elaboración propia.

Sobre los canales con mayor número de suscriptores observamos que por Comunidades Autónomas, los Ayuntamientos situados en la costa de Levante (Cataluña, Comunidad Valenciana y Región de Murcia) son mayoritarios, seguidos de Andalucía, Castilla y León y Aragón. Por año de creación, 2020 ha sido el año en el que han aparecido poco más de la mitad de los canales con más seguidores. Estos datos pueden observarse en detalle en la Tabla 4.

Tabla 4. Resultados por Comunidades Autónomas y año de creación.

\begin{tabular}{|c|c|c|}
\hline \multicolumn{2}{|c|}{ Resultados por Comunidades Autónomas } \\
\hline Autonomía & Canales & Porcentaje \\
\hline Cataluña & 29 & $58 \%$ \\
\hline Comunidad Valenciana & 10 & $20 \%$ \\
\hline Región de Murcia & 5 & $10 \%$ \\
\hline Andalucía & 3 & $6 \%$ \\
\hline
\end{tabular}




\begin{tabular}{|c|c|c|}
\hline Castilla y León & 2 & $4 \%$ \\
\hline Aragón & 2 & $4 \%$ \\
\hline \multicolumn{3}{|c|}{ Resultados por fecha de creación } \\
\hline Año & Canales & Porcentaje \\
\hline 2020 & 26 & $52 \%$ \\
\hline 2019 & 15 & $30 \%$ \\
\hline 2018 & 5 & $10 \%$ \\
\hline 2017 & 5 & $10 \%$ \\
\hline
\end{tabular}

Fuente: Elaboración propia.

El porcentaje de respuesta obtenido del cuestionario por Comunidades Autónomas (en adelante CC.AA.) es el siguiente: de las 29 respuestas obtenidas 11 pertenecen a Cataluña (Castellbisbal, Centelles, Prat de Llobregat, Canet de Mar, La Vall d'en Bas, El Vendrell, Torelló, Vacarisses, Lleida, Palafrugell y Castellar del Vallés) lo que corresponde al 37,9\% del total de canales de la muestra por CC.AA.; 8 a la Comunidad Valenciana (Sueca, Catarroja, Ademuz, Xàbia, La Vall d’Uixó, San Vicente del Raspeig, Benicarló y La Nucía) siendo el $80 \%$ de la muestra por CC.AA.; 4 a la Región de Murcia (Alcantarilla, Lorca, Yecla, y Los Alcázares) correspondiendo también al 80\% de la muestra por CC.AA.; 2 de Andalucía (Sevilla y Cártama) siendo el 66\% por CC.AA.; 2 de Castilla y León (Ciudad Rodrigo y Valencia de Don Juan) y 2 de Aragón (Calatayud y Alcañiz). De estos últimos el porcentaje de respuesta fue del $100 \%$.

Analizadas las respuestas de los cuestionarios en base a las etiquetas los porcentajes de coincidencia en las respuestas son los que se resumen en la Tabla 5.

Tabla 5. Resultados encuestas.

\begin{tabular}{|c|c|}
\hline Etiqueta & Coincidencia \\
\hline Apertura durante la crisis & $28 \%$ \\
\hline Aumento de suscriptores & $66 \%$ \\
\hline Directo & $100 \%$ \\
\hline No hay ruido & $34 \%$ \\
\hline Privacidad & $21 \%$ \\
\hline Infografías & $66 \%$ \\
\hline Todo tipo de formatos & $28 \%$ \\
\hline Gestión profesional desde el Ayuntamiento & $93 \%$ \\
\hline
\end{tabular}

Fuente: Elaboración propia.

El $28 \%$ de los Ayuntamientos abrieron durante la crisis sanitaria de la COVID-19 sus canales de Telegram. La creación y lanzamiento se produjo durante las primeras semanas del estado de alarma. Un 7\% contestaron que pusieron en marcha el canal 
durante la crisis de la DANA que se produjo en el mes de septiembre de 2019. Otros explican que abrieron como complemento al resto de perfiles de redes sociales municipales que ya poseían en Facebook, Twitter e Instagram. En estos casos la apertura se produjo durante los años 2017, 2018, 2019 y 2020, siendo este último el año en el que más se abrieron.

En relación al aumento de suscriptores con la crisis sanitaria generada por la COVID-19, el $66 \%$ opina que sí que guarda una relación directa. Sobre esta cuestión destaca que la gran mayoría de consistorios establecieron el canal de Telegram como herramienta principal de difusión de las medidas e información municipal referente a la COVID-19. Acción de la que muchos de ellos explican que hicieron un llamamiento a la ciudadanía desde el resto de redes sociales a seguir el canal de Telegram para estar informados de la última hora. En la imagen 1 se muestran diferentes ejemplos de publicaciones de la cuenta de Twitter en Calatayud, una infografía elaborada por el Ayuntamiento de El Prat de Llobregat, y una publicación de Instagram del perfil de San Vicente del Raspeig, donde se combina la publicación de agenda diaria para hace un llamamiento a seguir el canal de Telegram municipal.

En referencia al aumento de suscriptores, el jefe de Comunicación del Prat de Llobregat destaca que la necesidad de la población en momentos de crisis de obtener información veraz en un mundo en un entorno donde se difunden bulos y noticias falsas porque "la ciudadanía ha demostrado suscribiéndose a nuestro canal que necesita combatir el auge de las fake news siguiendo fuentes de información fiable como lo han sido los canales de Telegram de las administraciones locales, como muestra la evolución de nuestro canal".

Todos los ayuntamientos coinciden en que la principal ventaja de los canales de Telegram es que son directos. Una característica que permite en situaciones de emergencia, donde la situación cambia hora tras hora, enviar información rápidamente y de forma directa a la ciudadanía. Con este aspecto destacan que el sistema de alertas en el móvil es una gran ventaja porqué avisa a los suscriptores de las novedades. Matizan que este aspecto de Telegram no genera rechazo hacia los suscriptores por dos 
motivos: el primero es que el sistema de alertas puede desactivarse; mientras que en segundo lugar explican que las personas que se unen al canal lo hacen porque están interesadas en recibir información de la institución.

Imagen 1. Ejemplos de publicaciones.

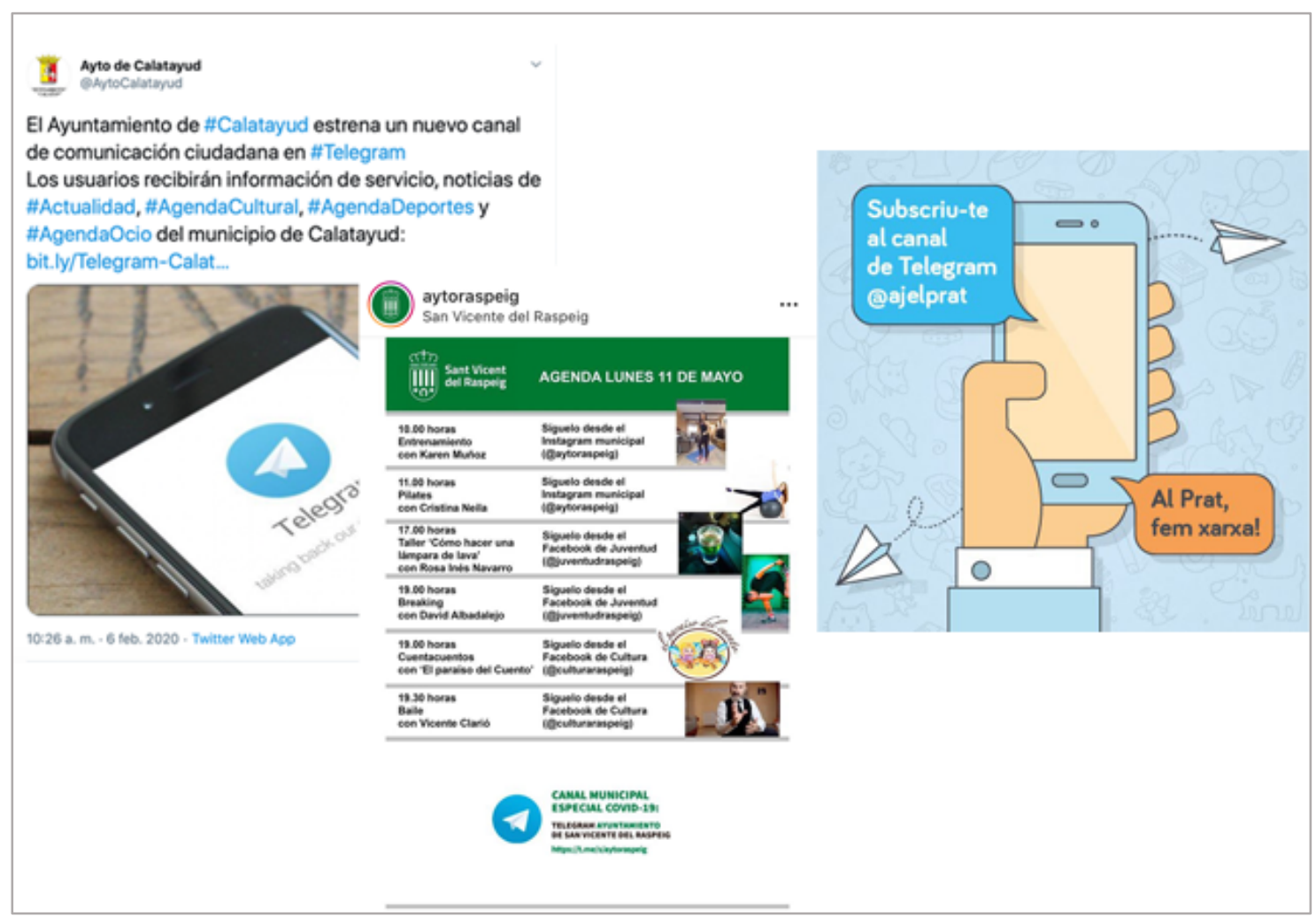

Fuente: Elaboración propia. Material obtenido del perfil de Twitter de Ayuntamiento de Calatayud (@AytoCalatayu), perfil de Facebook del Ayuntamiento del Prat de Llobregat (@ajuntamentdelprat), y del perfil de Instagram del Ayuntamiento de San Vicente del Raspeig (@aytoraspeig).

El aspecto de ser un medio directo lo relaciona el $34 \%$ de los ayuntamientos que han respondido coinciden en que la difusión desde los canales de Telegram no genera ruido, es decir, el hecho de ser un medio unidireccional no permite la interacción de la ciudadanía. Argumentan que los canales no son generadores de opinión, son meros transmisores de información. Para generar opinión y debate, donde la ciudadanía pueda participar se encuentran los perfiles de redes sociales en Facebook, Twitter o Instagram, donde se permite expresar opiniones o realizar preguntas directas con comentarios públicos o privados. 
La privacidad en un $21 \%$ de las respuestas (aunque en menor medida) también es una característica relevante de los canales de Telegram para sus gestores. Los responsables de comunicación destacan que para unirse a un canal dentro de esta herramienta de mensajería solamente es necesario un dispositivo electrónico (móvil, tableta u ordenador) con conexión a internet y tener la aplicación descargada. Además, no hay que realizar ningún trámite previo a la protección de datos, porque tal y como señala el concejal de Comunicación del Ayuntamiento de Valencia de Don Juan, "a diferencia de las listas de difusión de WhatsApp, Telegram no precisa la solicitud previa del teléfono a ninguna persona y poder tener problemas por la gestión de la privacidad y protección de datos".

En cuanto al contenido, el $66 \%$ coinciden en que han difundido la información sobre las medidas y última hora sobre la COVID-19 en la localidad utilizando infografías. Esta representación gráfica complementada con un pequeño texto directo, informativo y resumido han sido la herramienta protagonista a nivel comunicativo para los ayuntamientos. La facilidad de creación a través de plantillas; y de difusión, ya que una vez lanzadas en el canal la ciudadanía podía compartir fácilmente con sus contactos, han sido los motivos que han hecho que los consistorios difundan en este formato la información de manera preferencial destacan en las respuestas.

Un 28\% explica que han usado el canal de Telegram para compartir la información en todo tipo de formatos: documentos PDF, vídeos, imágenes o enlaces. Según el tipo de información que tenían que comunicar elegían un formato u otro. Destacan que todo el material que han compartido ha sido información directa de servicio y de interés para la ciudadanía. En ningún momento se han difundido noticias completas municipales (estas eran compartidas desde enlaces a la web municipal) o información con contenido de carácter político.

Finalmente, sobre el lugar desde donde se gestiona el canal y la persona o personas encargadas de hacerlo, el 93\% afirman que, de las publicaciones en el canal, las personas encargadas son periodistas, diseñadores gráficos, asesores multimedia o expertos en social media. Estas personas ocupan puestos de funcionarios de carrera, personal 
laboral y eventual dentro del propio ayuntamiento. La gestión del 7\% restante se lleva a cabo de forma mixta, es decir, un profesional contratado de forma externa, pero que se encuentra muy vinculado al día a día del consistorio y en permanente contacto con el alcalde de la localidad o responsable político del área. Resaltar que la gestión por parte de concejales o alcaldes de los canales es escasa y suele darse en municipios con menor población como Ademuz (1.042 habitantes) o Valencia de Don Juan (5.321 habitantes). Además, también es de relevancia que existen localidades como Lorca, donde la edil responsable de Comunicación es periodista.

En cuanto al número de personas que gestionan los canales de Telegram suele oscilar entre 1 y 4 , según las respuestas obtenidas. El número de personas depende del número de habitantes de la localidad. El dato más relevante es que mayoritariamente los puestos de comunicación están ligados al gobierno local del momento siendo puestos en su mayoría de personal eventual por designación política. El perfil del puesto de técnico de Comunicación municipal se encuentra más consolidado, independientemente del número de habitantes, en las localidades de Cataluña, donde el $63 \%$ son empleados públicos.

\section{CONCLUSIONES}

Las aplicaciones de mensajería instantánea han jugado un papel protagonista durante la crisis sanitaria de la COVID-19. Indiscutiblemente, WhatsApp, es la herramienta bidireccional de este tipo más utilizada por el público, llegando a aumentar su tráfico de datos durante los primeros días del confinamiento un 698\% en España (laverdad.es, 2020). Si bien, en el ámbito de envío directo de información de forma unidireccional, Telegram, con sus canales de difusión, presenta mayores ventajas y es más fácil de usar por la persona/s responsable/s de la gestión porque no son necesarios trámites previos sobre protección de datos para que las personas se unan al canal.

El hecho de ser un canal directo con la ciudadanía y la facilidad para suscribirse son dos de los motivos principales por los que los ayuntamientos se han decantado por Telegram para difundir su información masivamente durante momentos de crisis. Se trata de un método unidireccional donde el principal objetivo es hacer llegar información veraz a 
los habitantes de un municipio. Una información que puede dar pie al debate y la participación ciudadana, acciones que reservan para los perfiles de redes sociales municipales como Facebook, Twitter o Instagram. Cada espacio o plataforma tiene un fin, y en el caso de los canales de Telegram municipales, este es difundir información. No existen aplicaciones de mensajería o redes sociales mejores o peores, sino que hay que adaptar el contenido al público que se mueve en cada una de ellas (López, 2020 B).

Las instituciones públicas deben comunicar aquella información que les demanda la ciudadanía en ese momento. La crisis de la COVID-19 ha puesto aún más de manifiesto la distinción entre comunicación institucional y comunicación política. Las personas que se unen al canal de Telegram de un ayuntamiento, así como a los diferentes perfiles de redes sociales, lo hacen motivados por una búsqueda de información actualizada sobre su ciudad. En ningún momento buscan información de carácter político. Esta última, en opinión de los encuestados, suele generar rechazo, sobre todo en una situación de crisis, por ello ha de reservarse para los perfiles de los políticos y de los diferentes partidos.

La comunicación y la realización de la misma desde los diferentes canales es una actividad profesional. Por lo tanto, las administraciones públicas a todos los niveles han de introducir estos perfiles profesionales en su relación de puestos de trabajo. Tradicionalmente, la comunicación ha estado ligada al personal eventual de designación política, un hecho que no debe continuar siendo así. "Las administraciones públicas están al servicio de la ciudadanía y de igual modo lo ha de estar la comunicación. Esta es una actividad a largo plazo que precisa de una planificación de modo que debe de estar contemplada dentro de las estructuras de puestos públicos de las instituciones. El personal eventual, debe ejercer una función de apoyo al político, en ningún momento ha de tener funciones ejecutivas dentro de la administración" (A. Ballester, comunicación personal, 16 de junio de 2020).

En este contexto, las entidades públicas han de hacer valer de todas las herramientas digitales a su alcance para hacer llegar la información que demanda la ciudadanía. Los profesionales que gestionan la comunicación han de saber cual de todas ellas es la más adecuada para cada momento. En el caso de una crisis como la generada por la 
pandemia de la COVID-19, la aplicación de mensajería instantánea Telegram, con sus canales de difusión, constituye una buena herramienta dentro de los ayuntamientos para difundir de forma rápida y directa la información de servicio que ha de conocer la ciudadanía al instante.

La presente investigación se planteó como objetivos conocer cuáles son los motivos que llevaron a los ayuntamientos a abrir sus canales de Telegram y qué papel han jugado estos durante la crisis sanitaria de la COVID-19. Hay que reconocer que el porcentaje de respuesta, aunque es representativo, en una situación de normalidad podría haber sido más elevado. Entendemos que las personas a las que iba dirigido el cuestionario han tenido una carga de trabajo muy elevada, no teniendo tiempo suficiente para responder al cuestionario. Por otro lado, los resultados obtenidos abren futuras líneas de investigación cómo el uso que las instituciones dan a los canales de Telegram en periodos que no son de crisis; o cuál es la tendencia en la cifra de de suscriptores en momentos de normalidad.

\section{REFERENCIAS BIBLIOGRÁFICAS}

Ayuntamiento de León (2020). El Ayuntamiento de León ofrece toda la información municipal a través del nuevo canal de Telegram. Aytoleon.es. Disponible en http://www.aytoleon.es/es/general/Lists/Calendario/DispFormDetalleNoticia.aspx?Lis $\mathrm{t}=034208 \mathrm{f} 2 \% 2 \mathrm{D} 546 \mathrm{f} \% 2 \mathrm{D} 4 \mathrm{cbc} \% 2 \mathrm{Db} 9 \mathrm{f} 6 \% 2 \mathrm{D} 487096 \mathrm{db} 9 \mathrm{c} 31 \& \mathrm{ID}=10768$

Barnes, J. A. (1954). Class and committees in a Norwegian Island Parish. Human Relations, 7, 39-58).

Bauman, Z. (2005). Vida Líquida. Barcelona: Austral.

Canel, M. J. (2018). La comunicación de la Administración Pública para gobernar con la sociedad. Madrid: Fondo de Cultura Económica de España.

Enrique, A. M. (2013). Communication management crisis in social networks. Revista Orbis, 24, 116-131. 
Espinosa, A. (2018). Irán prohíbe el uso de Telegram por "seguridad nacional". elpais.com. Disponible en https://elpais.com/internacional/2018/05/02/actualidad/1525270520 213289.html

Fernández, R. (2018). El móvil como propagador de las revueltas en Irán de diciembre de 2019. El caso de la red social Telegram. En Langa, C. y Ballesteros-Aguayo, L. (Eds.), Movimientos populistas en Europa: la actualización del discurso totalitario en los medios de comunicación actuales y su repercusión en la opinión pública. (pp. 123-137). Egregius.

Fernández, S. (2020). Primera Historia de la crisis del Coronavirus en España. La Razón Histórica. Revista hisponoamericana de Historia de las Ideas. 46, 12-22.

García, E. (2018). Instagram y Telegram bloqueados en Irán: la censura vuelve a cargar contra las aplicaciones. xatakamovil.com. Disponible en https://www.xatakamovil.com/movil-y-sociedad/instagram-y-telegram-bloqueadasen-iran-la-censura-vuelve-a-cargar-contra-las-aplicaciones

Gutiérrez-Rubí, A. (2020). Pautas para mejorar la comunicación en los Ayuntamientos [Webinar]. Diputación de Alicante y Fundación Democracia y Gobierno Global. Disponible en https://www.youtube.com/watch?v=vX28vOKyjTI\&feature=emb title Guzmán, B. (2018). Comunicación y salud: La gestión de la crisis del Ébola a través de las redes sociales. Revista española de la Comunicación en salud, 9(2), 196-202.

Koury, J.M., y Hirschhaut, M. (2020). Reseña histórica del COVID-19: ¿Cómo y por qué llegamos a esta pandemia?. Acta odontológica venezolona, 58, 3-4.

La Vanguardia (2019). El canal de Telegram de Tsunami Democràtic, entre lo que tiene más seguidores del mundo. Lavanguardia.com. Disponible en https://www.lavanguardia.com/politica/20191101/471312746093/telegram-tsunamidemocratic-seguidores-mundo.html 
La Verdad (2020). WhatsApp echa humo en el confinamiento. laverdad.es. Disponible en https://www.laverdad.es/tecnologia/whatsapp-echa-humo-confinamientoaplicaciones-consumo-redes-sociales-datos-20200328112232-ntrc.html

López, A. (2020a). El uso de Whatsapp y Telegram en las Administraciones Públicas. En amalialopezacera.com. Disponible en https://amalialopezacera.com/el-uso-dewhatsapp-y-telegram-en-las-administraciones-publicas/

López, A. (2020b). La Gestión de la Comunicación en las Administraciones Locales. [Webinar]. Mancomunidad de Municipios Bahía de Cádiz. Disponible en http://pf.bahiadecadiz.es/mmbc/pafc/PortalGFC.nsf?Open

López, A. (2020c). Listado de 71 canales de Telegram de Ayuntamientos (activos). amalialopezacera.com. Disponible en https://amalialopezacera.com/listado-de-71canales-de-telegram-de-ayuntamientos-activos/

Losada, J.C. (2010). Comunicación en la gestión de crisis. Lecciones prácticas. Barcelona: Editorial UOC.

Moltó, D. (2020). Comunicar en plena pandemia: del bando municipal a las redes sociales. En elmundo.es. Recuperado de https://www.elmundo.es/comunidadvalenciana/alicante/2020/04/07/5e8b5a9cfdddff97938b45ab.html

Red social. (2020). Diccionario del español jurídico. Madrid: Real Academia Española.

Ramírez, I. (2020). WhatsApp vs Telegram: ¿cuál es la mejor aplicación de mensajería? xatakandroid.com. Disponible en https://www.xatakandroid.com/aplicacionesandroid/whatsapp-vs-telegram-cual-mejor-aplicacion-mensajeria-1

Villar, J. (2016). Gestión y planificación de redes sociales profesionales: todo lo que debes saber para gestionar correctamente redes sociales corporativas. Barcelona: Deusto.

Westphalen, M. H. y Piñuel, J. L. (1993). La dirección de comunicación: prácticas profesionales: diccionario técnico. Madrid: Prado. 